\title{
Modelo de Mantenimiento Centrado en Confiabilidad para Plataformas de Telecomunicaciones y Transmisión de Datos
}

\author{
Maintenance Model Centered on Reliability towards \\ Telecommunication Platforms and Data Transmission
}

Juan José Oliveira Maurera ${ }^{1}$ https://orcid.org/0000-0002-84745872

César Omar Estaba Hernández ${ }^{1}$

${ }^{1}$ Universidad de Oriente, Maturín, Venezuela

juanjoliveiramegmail.com

cesarestaba@gmail.com

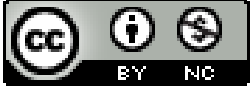

Esta obra está bajo una licencia internacional

Creative Commons Atribución-NoComercial 4.0. $\begin{array}{ll}\text { Enviado: } & 2021 / 01 / 19 \\ \text { Aceptado: } & 2021 / 04 / 28 \\ \text { Publicado: } & 2021 / 06 / 30\end{array}$

El objetivo de esta investigación fue concebir un cuerpo teórico y práctico para resemantizar el modelo de mantenimiento centrado en confiabilidad para su aplicación en plataformas de telecomunicaciones y transmisión de datos, lo que permite un nuevo enfoque metodológico para la gestión del mantenimiento en este tipo de infraestructura. Se trata de una propuesta innovadora en dos grandes aspectos: en primer lugar, en lo relativo a la adaptación del modelo de mantenimiento generado y su aplicabilidad en cualquier entorno tecnológico de telecomunicaciones y transmisión de datos, $\mathrm{y}$, en segundo lugar, respecto de la manera en que esta propuesta se reinterpreta mediante un marco conceptual particular ampliamente probado para su aplicación inédita en otros contextos tecnoproductivos. En cuanto al diseño operativo, se desarrolló una integración de la Metodología de Mantenimiento Centrado en Confiabilidad (MCC) y el Control Objetives for Information and Related Technology (COBIT). Como principal producto se generó un programa de mantenimiento con base en un nuevo esquema operativo denominado Metodología de Mantenimiento Confiable para Plataformas de Telecomunicaciones (MCPT), lo que constituye una herramienta innovadora para la prevención y el control de fallos en procesos de mantenimiento.

Palabras clave: Modelo de mantenimiento, mantenimiento centrado en confiabilidad, COBIT, telecomunicaciones, transmisión de datos.

\footnotetext{
Abstract

The objective of this research is to conceive a theoretical and practical body to resemanticize the maintenance model focused on reliability towards its application in telecommunication platforms and data transmission allowing a new methodological approach for the maintenance management of

Sumario: 1 Introducción, 2 Metodología, 3 Propuesta, 4 Discusión, 5 Conclusiones.

Como citar: Oliveira, J. J., \& Estaba, C. (2021). Modelo de Mantenimiento Centrado en Confiabilidad para Plataformas de Telecomunicaciones y Transmisión de Datos. Revista Tecnológica - Espol, 33(1), 49-70. http://www.rte.espol.edu.ec/index.php/tecnologica/article/view/801
} 
this type of infrastructure. It is an innovative proposal in two main aspects; firstly, regarding the adaptation of the maintenance model generated and its applicability to any telecommunications and data transmission technological environment, and secondly, the way in which it is reinterpreted through a particular conceptual framework widely tested for its unprecedented application in other techno-productive contexts. Regarding the operational design, integration of the Reliability Centered Maintenance Methodology (MCC) and the Control Objectives for Information and Related Technology (COBIT) was developed. The main product is a maintenance program based on a new operating scheme called Reliable Maintenance Methodology for Telecommunication Platforms (MCPT), representing an innovative tool for the prevention and control of failures in maintenance processes.

Keywords: Maintenance model, maintenance focused on reliability, COBIT, telecommunications, data transmission.

\section{Introducción}

Históricamente, las diversas necesidades del ser humano han impulsado la creación de entidades y estructuras destinadas a dar respuesta a esas exigencias. Muchas de las actividades que realizan las personas requieren del apoyo de terceros para poder llevarse a cabo de manera apropiada. Es coherente afirmar, entonces, que, a medida que aumenta el número de individuos, de igual manera crece la cantidad de organizaciones dispuestas a satisfacer sus necesidades.

Los desarrollos científicos van de la mano de la evolución social, económica, cultural, política y logística de la población; en este sentido, se presentan investigaciones y propuestas que van destinadas a la generación de nuevas estructuras o paradigmas científicos, que, a su vez, representan el soporte formal de las actividades llanas del mundo y sus habitantes.

El presente trabajo de investigación es, precisamente, un ejemplo de un proceso de generación de herramientas científicas para la atención de escenarios carentes o desprovistos de modelos formales que evalúen y mejoren sus estructuras, funcionamiento y desempeño. Esta investigación empleó la resemantización como guía para orientar y conducir su proceso de desarrollo y obtención de resultados. Tal como lo define Zecchetto (2011), resemantizar es un vocablo que "se refiere a la operación semiótica de transformar el sentido de una realidad conocida o aceptada para renovarla o para hacer una transposición de modelo, creando una entidad distinta, pero con alguna conexión referencial con aquélla, de modo que esta última asume un nuevo significado que la primera no tenía" (p. 127).

La decisión de trabajar sobre la resemantización a partir de los conceptos principales del modelo de mantenimiento centrado en confiabilidad para plataformas tecnológicas de telecomunicaciones y transmisión de datos se tomó debido a que las estructuras preestablecidas de estas no están diseñadas para tales sistemas.

La investigación estableció los elementos teóricos y prácticos para configurar la gestión de telecomunicaciones y transmisión de datos sustentada en el modelo de mantenimiento centrado en confiabilidad; esta arriesgada propuesta investigativa incorporó fundamentos de los sistemas mecánicos en los elementos característicos de sistemas abstractos; satisfaciendo así la necesidad científica que existe en el tratamiento y aseguramiento de la continuidad de los procesos relacionados con el manejo de la información y comunicación. En un pasado reciente, pero en otra área de conocimiento, Wither (2014) también planteó un plan de auditoría para un modelo de aerolínea doméstica con base en un análisis de riesgo y tomando como referencia el esquema operativo COBIT 5 , lo cual confirmó las ventajas de combinar herramientas tan disímiles para obtener mejores resultados.

Según Orbe (2017), la transmisión de datos en informática es, como su nombre lo indica, la transferencia de datos por un canal de comunicación. La naturaleza de los datos puede ser de tipo público o privado. La transmisión de datos en ambiente público es lo que se conoce, tradicionalmente, 
como internet, es decir, un proceso de transmisión de datos compartidos por un gran número de personas sin restricciones, salvo excepciones por políticas de países o culturas.

La telecomunicación es toda transmisión, emisión o recepción de signos, señales, textos escritos, imágenes, sonidos o informaciones de cualquier naturaleza generadas por hilo, radioelectricidad, medios ópticos u otros medios electromagnéticos afines, inventados o por inventarse (La Ley Orgánica de Telecomunicaciones de Venezuela, 2011). Esto deja en evidencia la multiplicidad de aplicaciones que tienen las telecomunicaciones, entre las cuales la transmisión de datos es una de las que mayor propagación y uso ha tenido en los últimos años, debido a la ubicuidad que posee esta, hoy por hoy, en los diferentes ámbitos de la vida.

Es así como, a nivel mundial, con algunas excepciones, entidades financieras, servicios gubernamentales de gestión pública, instituciones educativas, tiendas, servicios públicos y sistemas de entretenimiento, entre otros tantos, funcionan y desarrollan sus actividades rutinarias en el internet. Lo que empezó, hace ya casi 40 años, como un encargo del Departamento de Defensa de los Estados Unidos (DOD), es decir, la construcción de una red de computadoras para utilizarla como medio de comunicación entre las diferentes instituciones académicas y estatales de ese país; hoy en día, es una herramienta usada por más de 4.021 millones de personas, nada menos que el $53 \%$ de la población mundial.

Con cifras como las que se acaban de referenciar, es evidente que las plataformas tecnológicas de funcionamiento del internet y transmisión de datos crecen y se hacen más complejas cada día, generando un reto de operatividad y mantenimiento enorme. Por supuesto, este escenario demanda la incorporación de métodos y herramientas que ayuden a optimizar estas tareas para mejorar los resultados de estos sistemas.

La presencia y el impacto de plataformas de telecomunicaciones para la transmisión de datos en América Latina son un hecho significativo. Muy a pesar de que la mayoría de las economías de la región están por debajo de los niveles primermundistas y su media de velocidad de conexión a la web es una de las más bajas del mundo, estos países han venido trasladando al internet una parte importante de las actividades y tareas cotidianas y transaccionales de su población. Por ejemplo, en México, Brasil y Chile, se ha dado un lugar preponderante y especial a las TIC como herramienta de apoyo a la gestión pública, lo que los ha obligado a plantear una modernización tecnológica en forma transversal.

De acuerdo con los niveles de tráfico que maneja la Comisión Nacional de Telecomunicaciones (CONATEL), Venezuela es uno de los países latinoamericanos que más ha incrementado el uso de transmisión de datos a nivel privado y de internet. Desde hace algunos años, ha incursionado en el mercado del gobierno electrónico al implementar la automatización de los procesos de gobierno, como parte de las estrategias de bienestar al ciudadano. Hoy en día, a pesar de la crisis que atraviesa el país, y al margen de las deficiencias en reinversión, mantenimiento y actualización de las plataformas tecnológicas, el gobierno electrónico en Venezuela sigue estando vigente y operativo. Sin embargo, estas plataformas electrónicas se han convertido en el verdugo del ciudadano común que busca realizar algún proceso, pues el bajo rendimiento tecnológico de estas lo dificulta.

Una falla que derive en la caída o interrupción inesperada del servicio, con la recurrencia que se ha tornado regular en el país, genera un impacto negativo para un número importante de personas, y su desenvolvimiento cotidiano en el mundo, provocando no solo malestar e incomodidad en los usuarios, sino también consecuencias más severas, dependiendo del contexto en el que se esté empleando.

En este mismo orden de ideas, el mantenimiento empieza a perfilarse como la piedra angular que falta en esta ecuación. Rivas (2017) propuso un modelo teórico para un sistema de gestión de mantenimiento basado en los principios de la gerencia de proyectos, buscando, con ello, reinventar la administración del mantenimiento con el objetivo de obtener su mayor provecho. Los modelos de mantenimiento anteriores se diseñaron en un momento en que los sistemas críticos que había que 
atender eran de otra naturaleza, por lo que se volvieron obsoletos para los nuevos tipos de plataformas tecnológicas de transmisión de datos, tan disímiles en sus variables, parámetros de entrada y funcionamiento (García, 2015; Bravo, 2016).

El actual modelo de mantenimiento centrado en confiabilidad, como herramienta de ingeniería, está concebido, según Mora (2009), para ser aplicado a sistemas mecánicos con naturalezas físicas muy distintas a las plataformas de transmisión de datos. Las variables que este modelo contempla son variables físicas clásicas, como presión, temperatura, corrosión, vibración y lubricación, entre otras.

Es evidente que, para atender y dar soporte a las nuevas plataformas de transmisión de datos, es ineludible reinventar el modelo de mantenimiento de confiablidad a fin de que se acople a estas, $y$, de este modo, se puedan generar resultados válidos y aplicables. Muy a pesar de que se hayan realizado algunos análisis y aportes en este sentido, estos han venido a atender casos puntuales y de manera circunstancial, dejando aún un vacío en cuanto a la existencia de una estructura metodológica y operativa que se establezca como perdurable y que, al mismo tiempo, sea flexible y pertinente para plataformas de esta índole.

Los problemas de mantenimiento y reinversión afectan considerablemente la mayoría de los servicios públicos y privados que se ofrecen en el país. Y, aunque también se les puede atribuir otras causas internas y externas, es indudable que no se han seguido protocolos apropiados de mantenimiento de equipos y servicios en áreas fundamentales que inciden directamente en la calidad de vida del venezolano, como, por ejemplo, el sistema eléctrico nacional, la distribución de agua potable, el suministro de gas doméstico y combustible y los servicios de conexión de voz y datos, entre otros.

Las telecomunicaciones impactan directa o indirectamente en todos los sectores productivos de una nación y, por consiguiente, afectan la calidad de vida de sus habitantes; por ello, hay que tomar en cuenta todos los elementos que han impedido el normal desarrollo de este importante sector: desinversión, politización, escasa capacidad técnica y operativa, legislación, control de precios de servicios y acceso a financiamientos y divisas, entre otros; razones que hacen necesario establecer nuevas políticas operacionales que garanticen la continuidad de los servicios de telecomunicación y transmisión de datos.

Por todo lo aquí descrito y expuesto, se hace inminente tomar acciones concretas de cara a atender esta grave situación. En este sentido, se propuso la puesta en marcha de esta investigación para generar una resemantización del modelo de mantenimiento centrado en confiabilidad que derive en una estructura metodológica que combine lo teórico y lo práctico, y que pueda ser aplicada a cualquier medio o sistema de telecomunicación y transmisión de datos, convirtiéndola así en una herramienta innovadora de gran proyección para la prevención y el control de fallos en los sistemas.

\section{Metodología}

El presente trabajo está enmarcado dentro de la modalidad Investigación proyectiva, puesto que esta permite una posible solución o mejora a la situación presente en el mantenimiento de plataformas de telecomunicaciones y transmisión de datos, mediante la puesta en marcha de procesos de búsqueda y pesquisa conforme con las características actuales de este tipo de tecnologías.

En relación con la Investigación proyectiva, Hurtado (2007) expresa lo siguiente: "este tipo de investigación propone soluciones a una situación determinada a partir de un proceso de indagación. Implica explorar, describir, explicar y proponer alternativas de cambio, más no necesariamente ejecutar la propuesta".

El nivel de la investigación, según Arias (2006), se refiere al grado de profundidad con que se aborda un objeto o fenómeno. En esta investigación se enmarca dentro del nivel comprensivo, debido a que esta presenta una explicación para distintos aspectos dentro de las plataformas de 
telecomunicaciones y transmisión de datos, además de que permite entender, proveer, pronosticar, exponer, diseñar, construir y formular una propuesta de solución a la problemática planteada.

De igual forma, se trabajó utilizando como población referencial al personal de la Unidad de Mantenimiento y Operaciones de Transmisión y Datos de Compañía Anónima Nacional Teléfonos de Venezuela (CANTV)-Monagas; y, más específicamente, con los trabajadores adscritos a este departamento que laboran de forma directa con los procesos de gestión de la plataforma tecnológica. En consecuencia, esta población referencial estuvo constituida por 12 individuos, conformados de la siguiente manera: dos (2) supervisores, dos (2) técnicos especialistas y ocho (8) técnicos de mantenimiento integral; además, considerando que dicho estamento es pequeño, se tomó un tipo de muestreo opinático de la totalidad de esta población, lo que permitió obtener la información requerida para alcanzar los objetivos propuestos.

Para la ejecución de este trabajo, tomando en cuenta que no existen antecedentes de este tipo de investigación, se estableció un esquema metodológico inédito, que permitió cubrir a cabalidad todas y cada una de las metas y los objetivos trazados. En tal sentido, con la integración de la Metodología de Mantenimiento Centrado en Confiabilidad (MCC) (Villacrés, 2016) y el Control objetives for informations and related technology (COBIT) (Balladares, 2017), se lograron alcanzar los objetivos específicos establecidos en esta investigación. Esta fusión respondió a las necesidades funcionales de la investigación, como el diseño de un marco operativo que orientara las actividades desarrolladas. La metodología MCC fue seleccionada debido a que constituye una herramienta que facilita que un equipo multidisciplinario optimice la confiabilidad operacional de un sistema cuyo funcionamiento se desarrolla bajo condiciones de trabajo definidas, estableciendo las actividades más efectivas de mantenimiento en función de la criticidad de los activos pertenecientes a dicho sistema.

De igual forma, COBIT, al tratarse de una metodología de auditoría informática e infraestructura tecnológica de gran escala y a todo nivel, aporta puentes entre los riesgos, los controles y los aspectos técnicos de un determinado negocio. Las fases resultantes de esta integración metodológica se presentan bajo la siguiente denominación: I. Identificación de parámetros, II. Estudio de infraestructura, III. Análisis de fallos y criticidad, IV. Diseño del plan y V. Reconceptualización. A continuación, una breve descripción de cada una de ellas.

\section{Fase I: Identificación de parámetros}

Consistió en establecer una base conceptual para un marco de trabajo que integre los elementos característicos de una filosofía de mantenimiento con políticas aceptadas para la gestión de plataformas de telecomunicación. Buscó proveer un esquema operativo integral que ayude a las empresas a alcanzar los objetivos relacionados con el mantenimiento de estructuras de telecomunicación y transmisión de datos. En esta fase se presentaron las siguientes actividades: estudio de la base conceptual metodológica, diagnóstico del entorno tecnológico, comparación contextual, identificación de elementos pertinentes, adaptación de recursos, definición de requerimientos y construcción metodológica.

\section{Fase II: Estudio de infraestructura}

Mediante diversas inspecciones de campo y una profunda revisión documental, se estableció un diagnóstico generalizado del contexto actual de las infraestructuras tecnológicas estudiadas. Se evaluaron los recursos disponibles y los nuevos requerimientos para optimizar el desempeño de las plataformas de transmisión de datos manteniendo el equilibrio entre la generación de beneficios y la minimización de los niveles de riesgos. En esta fase se presentaron las siguientes actividades: estudio del entorno, revisión de aspectos legales, análisis de recursos disponibles y definición de requerimientos.

\section{Fase III: Análisis de fallos y criticidad}

Se determinaron todos los tipos de fallos y sus modos en las infraestructuras estudiadas; un 'fallo' es la incapacidad de un ítem para cumplir alguna de sus funciones, mientras que un 'fallo funcional' es aquel que impide al sistema en su conjunto cumplir su función principal. Finalmente, un 'fallo técnico' es aquel que, sin impedir al sistema cumplir su función principal, supone un 
funcionamiento anormal de una parte de este. Una vez determinados todos los fallos que se pueden presentar, se deben estudiar sus respectivos modos de fallo, lo que posibilita identificar las causas primarias de estos o las circunstancias en las que se produce un fallo específico.

Cada fallo, funcional o técnico, puede presentar múltiples modos de fallo; cada uno de estos puede tener a su vez múltiples causas, y estas, por su parte, otras, hasta llegar a lo que se denomina 'causas raíces'. Por lo tanto, fue importante definir con qué grado de profundidad se iban a abordar los modos de fallo para determinar si el estudio era viable o, técnicamente, factible. El siguiente paso fue determinar los efectos de cada modo de fallo para, luego, clasificarlos según la gravedad de las consecuencias. Esta fase incluye las siguientes actividades: determinación de fallos funcionales y técnicos, determinación de modos de fallos y análisis de criticidad.

\section{Fase IV: Diseño del plan}

Determinados ya los modos de fallo del sistema que se analizaron, y clasificados estos modos según su criticidad, el siguiente paso fue determinar las medidas preventivas que permitieran evitar el fallo o, al menos, minimizar sus efectos. Definidas las medidas preventivas, lo siguiente fue agrupar estas medidas por tipos (tareas de mantenimiento, mejoras, procedimientos de operación, procedimientos de mantenimiento y formación), lo que facilitó su posterior implementación. En esta fase se presentaron las siguientes actividades: establecimiento, revisión y agrupación de medidas preventivas, identificación de mejoras prácticas y definición de un plan de acción.

\section{Fase V: Reconceptualización}

Una vez identificadas las mejoras prácticas, estas debieron estructurarse en nuevos esquemas operativos, que incluyeron la optimización de los procesos, la adecuación del entorno y la formación continua del personal involucrado. Como un proceso de reflexión crítica, se evaluaron los resultados obtenidos, a partir de los cambios establecidos y recomendados, para lograr la adecuación y la redimensión técnica y operativa del mantenimiento centrado en confiabilidad como un apoyo de control en plataformas tecnológicas. En esta fase se desarrollaron las siguientes actividades: planificación de actividades de formación, definición de nuevos esquemas operativos, integración del plan de mantenimiento, análisis costo-beneficio, aplicación del plan, presentación de resultados, evaluación de la propuesta metodológica y la adecuación técnica y operativa del mantenimiento centrado en confiabilidad.

\section{Propuesta}

Este trabajo de investigación pretende sentar las bases para una resemantización de las filosofías de mantenimiento aplicado a plataformas de telecomunicación; llama la atención que, a pesar de todos los avances científicos y tecnológicos en esta era de la informática, aún no existan políticas estandarizadas para el mantenimiento formal de este tipo de plataformas. Quizás, precisamente por los súbitos cambios ocurridos en las últimas décadas en esta área del conocimiento, los entendidos no se han percatado de la trascendencia y la necesidad de contar con elementos probados para la ejecución efectiva de planes de mantenimiento en sistemas de telecomunicaciones y trasmisión de datos. A pesar de todas las consecuencias que pudiera generar una interrupción en el servicio de transmisión de datos, no se han desarrollados planes para el tratamiento de los datos en estos nuevos escenarios o esquemas de operación, claves para garantizar la calidad del servicio.

Probablemente lo anterior ocurre porque el tráfico y manejo de información son procesos intangibles, que, muchas veces resultan "invisibles", a diferencia de las operaciones productivas con dispositivos o maquinarias físicamente establecidas que han acompañado tradicionalmente a la industria, lo que ha requerido la implementación de una gerencia de mantenimiento apropiada dentro de las instalaciones donde operan.

\section{Fase I: Identificación de parámetros}

Para intentar lograr esta adaptación del modelo de mantenimiento -normalmente utilizado en equipos y maquinarias- al contexto de la trasmisión de datos, se utilizó el concepto de resemantización para dar un nuevo sentido a la configuración en este tipo de sistemas, es decir, 
redefinir el significado del mantenimiento, en este caso particular, centrado en confiabilidad, como una nueva propuesta que pretende reformular, reproducir y redimensionar las posibilidades de mantenimiento a plataformas de telecomunicaciones existentes en la actualidad, lo cual genera una opción de trabajo que garantiza un mayor control del servicio bajo un esquema de trabajo versátil, indispensable y de gran proyección en cualquier tipo de organización.

La resemantización, en sí misma, no es una propuesta nueva; lo innovador radica en el contexto específico donde se quiere aplicar. El ser humano por su propia naturaleza siempre ha buscado la forma de reinventar sus recursos para sacarles el mayor provecho posible; la reinterpretación de todas las habilidades, culturas, ideas, herramientas ha sido clave en la evolución y adaptación del ser humano.

En tal sentido, la resemantización del modelo de mantenimiento centrado en confiabilidad, para dar respuesta a las exigencias de una nueva estructura operativa en el manejo de la información enmarcada en distintos contextos tecnológicos, permite dar un nuevo efecto al mantenimiento que supera a los procedimientos ya existente en este campo; transformar o readaptar el sentido del mantenimiento industrial en nuevas plataformas representa un gran aporte porque permite aprovechar todas las técnicas comúnmente utilizadas en la gestión de mantenimiento del control de procesos, equipos y dispositivos dedicados para la trasmisión de datos; mediante esta reutilización de esquemas funcionales se genera un nuevo enfoque metodológico "revolucionario" para desarrollar planes innovadores de mantenimiento en este tipo de escenarios.

A continuación, se presenta información recabada en la revisión técnica y documental de datos contenidos en diversas fuentes físicas y electrónicas de la empresa CANTV y, en general, del proceso de trasmisión de datos en Venezuela.

Una característica relevante de las tecnologías en telecomunicaciones es la convergencia entre las diferentes redes de transmisión fija y móvil y de voz y datos. En la actualidad, la integración de estas redes de banda ancha es indispensable para atender los variados servicios que los usuarios demandan para sus smartphones, aplicaciones móviles y para acceder a múltiples servicios e información en áreas como salud, transporte, logística, finanzas, entretenimiento, seguridad, gobierno, comunicación y casi todas las industrias y servicios. Esto representa un importante promotor del desarrollo social y económico del país.

En general, la industria de las Telecomunicaciones y Tecnología de la Información (TIC) es uno de los pilares fundamentales del desarrollo económico y social de un país. El sector de las TIC pone a disposición de los usuarios una gran cantidad de servicios de gran demanda, lo que ha impulsado el surgimiento de un elevado número de empresas relacionadas con las operadoras de estos servicios. Las empresas que prestan servicios de tecnología de información y comunicaciones para su sostenibilidad deben procurar la competitividad, la productividad y la calidad de sus servicios, pero, adicionalmente, deben considerar que la generación y consolidación de ventajas competitivas, al interior de una empresa, guarda una estrecha vinculación con las condiciones del entorno.

La inversión en tecnología, que es una de las bases fundamentales del crecimiento y desarrollo de un país, es muy inferior a la mínima necesaria, y, sobre todo, en aquella destinada a la capacitación del recurso humano del sector. Es importante destacar que no es suficiente tener la provisión de infraestructura de TIC para el acceso a la información, sino que también es indispensable tener las condiciones y competencias específicas que permitan aprovechar la oportunidad que brinda ese conocimiento para la creación de valor por parte de las empresas y los organismos. En el caso venezolano, tanto la infraestructura como el talento humano han quedado rezagados por todos los problemas políticos y socioeconómicos que afectan a este país actualmente.

Hoy día se dispone de varias formas de conexión a internet, desde un lugar fijo o desde dispositivos móviles. En el primer caso, la conexión más habitual es Asimetric Digital Suscriber Line (ADSL), transmitida a través de la red telefónica con una velocidad de hasta 2 Mbps; este tipo de conexión en el país se denomina Acceso Banda Ancha (ABA), y es un servicio prestado por la 
CANTV. Existen versiones mejoradas de esta tecnología, como ADSL2 y ADSL2+, con capacidad de suministro de televisión y video de alta calidad, y con velocidades de transmisión de hasta 24 Mbps, evitando con ello las interferencias o el ruido y disminuyendo los efectos de la atenuación.

Para disponer de un mayor ancho de banda, se presenta un gran obstáculo: la distancia entre el cliente y el equipo terminal. Para contrarrestar esta dificultad surgen alternativas, como las opciones de red con cable coaxial y fibra óptica. En particular, la disponibilidad de fibra óptica tiene un impacto negativo directo en los parámetros de calidad del servicio derivados de variables, como la latencia o el retardo en el tráfico.

Es importante comprender este último concepto de la latencia o del retardo como el tiempo que toma un paquete de información en llegar a su destino y regresar; así como la confiabilidad en la disponibilidad del enlace, entendida como la proporción de transmisiones de datos fallidas y proporción de accesos con éxito, juegan un papel fundamental en la calidad del servicio. En el segundo caso, el de la conexión móvil establecida mediante equipos móviles smartphones se dispone de conexión a Internet con tecnología $2 \mathrm{G}$ o de segunda generación, con velocidades que alcanzan hasta $232 \mathrm{Kbps}$ y soportan protocolos Global System for Mobile Communications (GSM), Code Division Multiple Access (CDMA), Time Division Multiple Access (TDMA), General Packet Radio Service (GPRS). Como una mejora de las redes $2 \mathrm{G}$ en la tasa de transferencia de datos, se ha introducido la tecnología Enhanced Data Rates for GSM of Evolution (EDGE), que funciona en cualquier red con protocolo GPRS y proporciona una cobertura inalámbrica más robusta que la $2 \mathrm{G}$, con velocidades de transferencia de entre 56 a 114 kbps.

La conectividad permanente inalámbrica $3 \mathrm{G}$ o de tercera generación, que tenía como objetivo facilitar la transferencia de archivos multimedia, alcanza una velocidad de hasta 2 Mbps y utiliza la tecnología Wideband Code Division Multiple Access (W-CDMA) para la transmisión de datos. El $3.5 \mathrm{G}$, considerada como una versión mejorada de 3G, alcanza una velocidad de transmisión igual a 14 Mbps, lo que permite la transmisión de video en vivo (streaming).

La tecnología 4G o de cuarta generación, también conocida por muchos fabricantes como Long Term Evolution (LTE), es mucho más veloz que las anteriores; su velocidad puede llegar a 100 Mbps para descarga y $50 \mathrm{Mbps}$ para carga. Sin embargo, este tipo de conexión no se utiliza ampliamente, ni todos los terminales ni todas las tarjetas SIM son compatibles con esta. Por su parte, la tecnología 5G llegó para revolucionar las comunicaciones. Aunque en Venezuela no está disponible esta nueva generación de transmisión y conexión de datos, ha empezado a dar sus primeros pasos en 2019.

Esta tecnología presenta mayor velocidad de conexión y tiene la capacidad de relacionar al mismo tiempo nuevos elementos, ubicaciones y servicios. El 5G será clave para el desarrollo de las ciudades inteligentes, las telecomunicaciones, la domótica, la industria 4.0, la automoción, el transporte, etc. En general, el 5G permitirá tener más dispositivos conectados. En la práctica esta tecnología no trae nada nuevo, sino tan solo una evolución con respecto a la generación que actualmente está más extendida, el 4G. Su llegada expresa el inicio de una nueva era de conectividad inteligente en el mundo, que, junto con los nuevos desarrollos en Internet: Big Data e Inteligencia Artificial, está a punto de ser un motor clave del crecimiento económico en los próximos años.

Sin embargo, no solo será más veloz, sino que conseguirá reducir el consumo energético en un $90 \%$. Es decir, los dispositivos conectados tendrán una mayor autonomía con la misma capacidad y con una cobertura casi del $100 \%$. Estos números reflejan una realidad muy distante en comparación con las antiguas redes. La 1G, por ejemplo, solo realizaba llamadas, mientras que la tecnología $2 \mathrm{G}$ introdujo el envío SMS. Recién a partir de la incorporación de la tecnología 3G se dio apertura al acceso del internet desde los dispositivos móviles; y, con la tecnología 4G, el teléfono se convirtió en smartphone, es decir, se pudo contar con un dispositivo capaz de integrar muchas funcionalidades que estaban ausentes en la tecnología anterior, por ejemplo, la reproducción de vídeos en tiempo real. 
Los sectores productivos, los gubernamentales y la sociedad en general están altamente interesados en el desarrollo y la implantación de la red 5G. La conexión inalámbrica es un activo de potencial ilimitado, al que nadie está dispuesto a renunciar; por el contrario, su implementación ha generado grandes expectativas, acordes con las nuevas exigencias. Por ello, las prestadoras de servicios están cada vez más interesadas en incorporar a sus esquemas operativos y de mantenimiento tecnológico todos los avances científicos, con el objetivo de brindar el mejor servicio posible de telecomunicaciones, de acuerdo con estándares internacionales y en el marco de las normativas vigentes.

Al incluir significativos avances tecnológicos, Venezuela, según datos recopilados por Romero (2019), había logrado alcanzar valores de velocidad de conexión por encima del promedio regional, sin embargo, al contar con este parámetro en los últimos años se ha venido deteriorando de forma alarmante, debido a la saturación del servicio originado por la creciente demanda y una infraestructura que no ha sido actualizada y ampliada para satisfacer dicho crecimiento. Esta velocidad promedio ha disminuido a $1.8 \mathrm{Mbps}$ en el año 2017, confirmándose el deterioro que viene experimentando la red móvil en Venezuela.

El sector de las telecomunicaciones en Venezuela se puede describir como un oligopolio de Estado, ya que, aun cuando existen empresas privadas, operadoras de diversos servicios, la competencia de estas con las empresas públicas es desigual. La empresa CANTV de servicios de telefonía fija, propiedad del Estado, cuenta con el $60 \%$ del mercado de internet, sin contar con la otra empresa estatal de telefonía móvil (MOVILNET). Ambas muestran una fuerte politización y dependencia del Poder Ejecutivo, y han disminuido su nivel de profesionalismo técnico con el que se desempeñaban.

Otro aspecto que se ha considerado para constatar el deterioro de la calidad del servicio de internet en estas empresas se refiere a la paulatina pérdida de confiabilidad de su servicio. Esto se refleja en la gran cantidad de reclamos y denuncias que presentan suscriptores residenciales y empresariales acerca de la indisponibilidad que, tanto de manera intermitente como permanente, presenta este servicio.

Estas fallas del servicio ocurren con el internet fijo, generando interrupciones que menoscaban la calidad de las telecomunicaciones. Estos inconvenientes son el resultado, principalmente, de las averías que se producen en la infraestructura de trasmisión de datos, debido a la ausencia de un plan de mantenimiento correctivo adecuado, que permita cumplir con las expectativas y exigencias de los usuarios. Este inexistente o precario mantenimiento de infraestructura TIC, que soporta el servicio de internet, se origina, fundamentalmente, por la escasez de equipos, la obsolescencia de la infraestructura y la poca preparación del personal que aún se mantiene en la empresa. Todo lo expresado, se puede explicar por los bajos niveles de inversión que ha recibido esta industria. La falta de inversión, de acuerdo con el criterio de un sector del país, se debe a la denominada "guerra económica" impuesta desde el exterior que ha tenido que afrontar el país y, por otros, debido a las políticas macroeconómicas inapropiadas (control de cambio, expropiaciones, desinversión, etc.) que desde el Estado se han aplicado.

Por otra parte, las principales empresas privadas que ofrecen servicio de internet fijo (IFX Networks, Ateweb, Etheron, Intercable, Netcom de Venezuela Ingeniería, S.A., RapidNet Service, C.A., Servicios OMNES de Venezuela, S.A., T-NET, WebMaxter, Únete Venezuela, Fision Net, Interamerican Net De Venezuela, S.A., IUSNET.NET, Link 7 e IPNet) y móvil (Digitel y Movistar) tampoco han realizado inversiones importantes para ampliar la infraestructura vinculada con el flujo de datos (red de fibra óptica), porque durante los últimos años estas empresas proveedoras de internet han debido afrontar los problemas derivados de la política pública con respecto al control cambiario y la escasez de divisas, además de un rezago tarifario, ocasionado por el bajo costo del servicio, que se ha ubicado muy por debajo del costo promedio internacional, Todo esto ha afectado a su capacidad de innovación y modernización de la red. 
Otro elemento que se debe destacar es las fiscalizaciones permanentes que ha sufrido el sector, especialmente por la intervención del organismo estatal regulador CONATEL, lo que ha podido provocar poca imparcialidad en sus decisiones y actuaciones. A continuación, se presenta un resumen de las debilidades encontradas en la organización; luego, en la Figura 1, se muestra un gráfico que muestra sus interconexiones.

Factores claves pesimistas:

1. Empresa dependiente del Ejecutivo Nacional

2. Desinversión en la infraestructura tecnológica

3. Presencia de mecanismos regulatorios

4. No existen estrategias de comunicación de indicadores oficiales

5. Baja calidad del servicio

6. Politización de la dirección y el sector en general

7. Baja rentabilidad del negocio

8. Falta de planes formales de mantenimiento

9. Dificultad para importaciones

10. Desprofesionalización de las empresas

11. Esquemas tarifarios inapropiados

En el gráfico se observa que existen factores cuyos grados de afectación en otros niveles son considerables; en este grupo se incluyen: presencia de mecanismos regulatorios; politización de la dirección y del sector en general; baja rentabilidad del negocio; falta de planes formales de mantenimiento y esquemas tarifarios inapropiados.

Al igual que en el análisis de factores claves pesimistas, en la siguiente figura se presenta la relación directa de cada uno de los elementos optimistas y sus interdependencias. Este análisis, realizado por el autor de esta investigación, da como resultado un análisis integrador que establece la influencia que tiene cada factor con respecto al resto. De igual forma, a continuación, se muestra un resumen de las fortalezas encontradas; luego, en la Figura 2, se ilustra un gráfico con las interconexiones correspondientes.

Figura 1

Interconexión de factores claves pesimistas

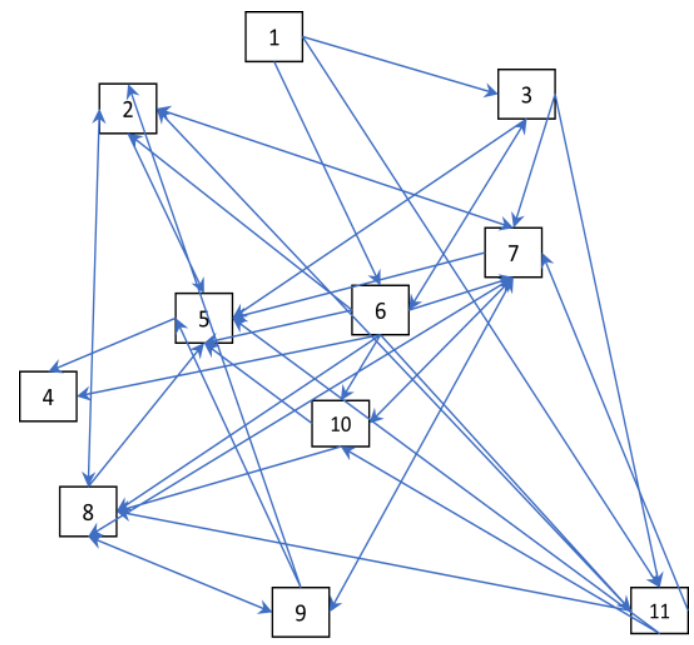

Fuente: Elaboración propia

Factores claves optimistas:

1. Imagen corporativa

2. Entorno del negocio

3. Alianzas estratégicas con otras instituciones 
4. Creciente demanda de servicios

5. Liderazgo en el mercado

6. Diversidad de ofertas

7. Capacidad técnica instalada

8. Talento humano

9. Respaldo del Estado

Figura 2

Interconexión de factores claves optimistas

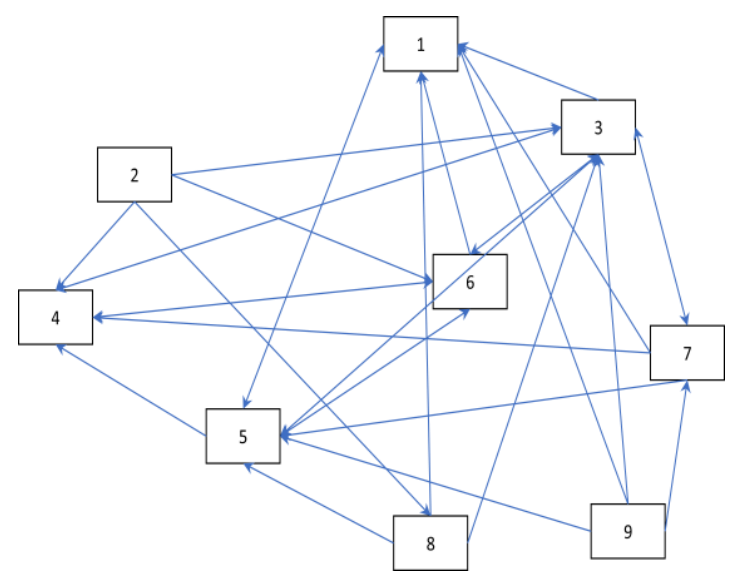

Fuente: Elaboración propia

En la figura anterior se puede apreciar de modo evidente cómo ciertos factores afectan considerablemente a otros; ahora, en este grupo, se incluyen los siguientes elementos: entorno del negocio, alianzas estratégicas con otras instituciones, liderazgo en el mercado, diversidad de ofertas, capacidad técnica instalada y respaldo del Estado.

\section{Fase II: Estudio de infraestructura}

Actualmente, CANTV -dentro de un ambiente de trabajo complejo debido a la grave crisis social y económica que afronta el país-continúa incorporando elementos a la red NGN (nueva generación) acorde a su plan de crecimiento, lo que a su vez requiere una alta inversión en capital humano especializado y recursos financieros. Por otro lado, esta adquisición de equipos de diversas marcas ha traído consigo el uso de la denominada tecnología aislada, lo que ha dificultado todavía más la implementación de políticas acertadas de mantenimiento debido a los requerimientos que esta variedad de marcas y diseños demanda, como su integración y mantenimiento a corto, mediano y largo plazo. Además, cabe recalcar, que la calidad de los repuestos o equipos disponibles en el mercado no garantizan los trabajos de mantenimiento necesarios en este tipo de infraestructuras.

El personal que conforma las diferentes gerencias de operaciones se encuentra desasistido de políticas perdurables de mantenimiento, ya sea porque no son factibles en la actualidad o, simplemente, porque la operatividad del día a día, que debe atender solo situaciones correctivas urgentes o prioritarias, las deja a un lado. Actualmente, la eficiencia en la gestión de redes y servicios de CANTV está comprometida debido a un modelo de gestión tradicional que utiliza grupos de tecnologías aislados, incapaces de establecer mejoras prácticas en la gestión de TIC, a partir de la implementación de planes de mantenimiento eficiente que garanticen la optimización de los recursos y la calidad del servicio. Es necesario resaltar que las mejoras en el servicio no dependen tan solo de una evolución tecnológica que sustituya la infraestructura obsoleta por una nueva. Hay que considerar que la ventaja competitiva en el sector de las telecomunicaciones y trasmisión de datos se fundamenta en el establecimiento de una gestión efectiva sobre el mantenimiento de sus plataformas y servicios que garantice la confiabilidad en sus operaciones. 
CANTV cuenta con muchas fortalezas, sin embargo, al momento de gestionar fallos que requieren de la participación coordinada de varias dependencias en la planificación de actividades y la disponibilidad de equipos, surgen dificultades para articular el trabajo de los departamentos debido a que cada uno de estos se maneja con procedimientos distintos. Como opción para disminuir los fallos recurrentes y mejorar considerablemente los tiempos de respuestas, la empresa ha fortalecido la gestión de la unidad de soporte técnico, haciéndola compartir experiencias y conocimientos con el resto del personal cuando se presenta algún inconveniente. Por ello, estandarizar y documentar estos procesos dentro de unas políticas formales de operación claras facilitaría el desarrollo de planes de mantenimiento de las plataformas de telecomunicación con nuevos criterios de mantenibilidad y confiabilidad.

En cuanto al inventario o a la identificación de equipos y materiales empleados tradicionalmente por CANTV para sus operaciones de mantenimiento, se presentan a continuación los recursos más utilizados:

\section{Equipos:}

- $\quad$ Equipos de computación para la gestión de averías

- Vehículos para traslado a sitio

- $\quad$ Escaleras expandibles

- $\quad$ Cinturón de seguridad

- $\quad$ Material de seguridad: casco, botas, lentes y guantes de seguridad

\section{Materiales:}

- $\quad$ Piqueta: herramienta para picar cable de red

- Jumper: cable para realizar lazos y cruzadas

- $\quad$ Conectores UY: herramienta para empalmes de hilos de cobre

- Destornilladores: pala y estría

- $\quad$ Ponchador: herramienta que se utiliza para reajustar cables de cobre en regletas dentro de los armarios y nodos

- Hexagonal: herramienta para reajustar el ramal en los módulos de los terminales

- Microteléfono: para verificación de tono

- Generador y localizador de tono

- Ramal: cable para instalación de líneas externas

- $\quad$ Goma gris: para instalación de líneas internas (FXB)

- $\quad$ Navaja: herramienta para desmembrar calves de cobre

- $\quad$ Alicate electricista

- $\quad$ Flejadoras

- $\quad$ Pinza de corte

- $\quad$ Llave de tanquilla

- $\quad$ Eslinga

- $\quad$ Llave de tanque

- $\quad$ Tester Loop

\section{Servidores utilizados}

Para el análisis de los equipos de servidores utilizados por la corporación se tomará como referencia aquellos relacionados con los componentes instalados para el monitoreo de la seguridad tecnológica. Esto debido a que estos servidores son de amplio dominio público y de fácil identificación. El resto de la plataforma tecnológica de la empresa se maneja de forma confidencial, pues maneja la información de la que dependen la mayoría de los venezolanos y el Estado en general.

Para cumplir tal propósito, la plataforma de seguridad de monitoreo cuenta, actualmente, con 15 servidores desplegados en toda la red corporativa de CANTV, de los cuales 13 corresponden a sensores IDS y 2 a consolas de visualización de eventos de seguridad SNORT y LML. A continuación, se describe brevemente su funcionamiento: 
Sensores IDS: dispositivos encargados de registrar todo el tráfico que circula en las diversas redes de CANTV, que luego analiza y compara por medio de diversos patrones de tráfico malicioso para generar diversas alertas de seguridad, que son almacenadas en las consolas de visualización para este tipo de eventos.

Consolas de visualización de eventos de seguridad: en la consola SNORT se muestran las alertas de virus y los ataques informáticos en contra de las redes y los elementos de tecnología de la información de CANTV; entretanto en la consola LML se muestran las alertas generadas por los logs de los dispositivos informáticos instalados en la red de CANTV y sus empresas filiales.

\section{Fase III: Análisis de fallos y criticidad}

La adaptación o nueva concepción del modelo de mantenimiento centrado en confiabilidad para plataformas de telecomunicaciones y transmisión de datos debe recorrer la ruta del análisis de fallos y la evaluación de criticidad, elementos fundamentales en el estudio tradicional del mantenimiento que arroja resultados determinantes para la toma de decisiones y la generación de planes de mantenimiento; precisamente por ello, en esta resemantización también se recurre a estas técnicas para el estudio de fallos y niveles de criticidad en entornos físicos y lógicos destinados a la transmisión de datos.

Específicamente en esta fase se presentarán los fallos funcionales y técnicos identificados, para luego determinar su modo de fallos y su criticidad. Este procedimiento busca establecer los elementos clave que permitan la consolidación de un plan de mantenimiento centrado en confiabilidad adaptado a plataformas para la gestión de datos.

En este caso, el mantenimiento se centra en la estructuración de un conjunto de actividades que garanticen la continuidad de un servicio o el restablecimiento de su operatividad en el menor tiempo posible y al más bajo costo. Al asegurar los aspectos mencionados, se lograría mantener la disponibilidad de los recursos para la transmisión de la información, minimizando así los fallos y los costos producidos por posibles interrupciones no planificadas.

Para continuar con la propuesta, de acuerdo con la información obtenida producto de la observación directa, las entrevistas, las encuestas y los registros históricos no oficiales, se ha determinado que los equipos y materiales fundamentales para los procesos de mantenimiento dentro de la Corporación son equipos de computación (escritorio), vehículos, ponchadoras, micro teléfonos, tester loop y los servidores. El requerimiento de estos equipos de soporte se debe a la gran cantidad de fallos o interrupciones que normalmente presentan estos equipos. Esta situación demanda periódicamente actividades de mantenimiento que permitan garantizar un mínimo de operatividad, considerando el rol central que tienen estos equipos en los procesos de transmisión de datos y telecomunicaciones; las grandes dificultades en la gestión de la solución de averías reportadas en líneas telefónicas están relacionadas directamente a problemas existentes en los equipos mencionados.

En la Tabla 1 se presenta un resumen de los trabajos de mantenimiento realizados a los dispositivos seleccionados, y que evidencia lo expresado con anterioridad; entre tanto, la Tabla 2 muestra estos resultados enunciados en porcentajes.

Solo se identifican actividades relacionadas con los mantenimientos correctivos, preventivos y predictivos; los otros tipos de mantenimiento no están dentro de los proyectos establecidos en las planificaciones formales o informales de la organización.

A partir de la información anterior es posible distinguir el bajo porcentaje de actividades preventivas planificadas para los equipos y materiales de alto impacto con el objetivo de garantizar la continuidad de servicios de transmisión de datos; de igual manera, es nulo el esfuerzo que se evidencia en el desarrollo de actividades predictivas, por lo que en los planes de mantenimiento que se deberían proponer es necesario considerar esto como un factor determinante para mejorar las condiciones actuales. 
Tabla 1

Tareas de mantenimiento realizadas a los principales equipos y materiales

\begin{tabular}{|l|c|c|c|c|}
\hline $\begin{array}{l}\text { Equipo/tipo de } \\
\text { mantenimiento }\end{array}$ & Preventivo & Correctivo & Predictivo & Total \\
\hline $\begin{array}{l}\text { Equipos de } \\
\text { computación }\end{array}$ & 1 & 25 & 0 & 26 \\
\hline Vehículos & 3 & 24 & 0 & 27 \\
\hline Ponchador & 0 & 2 & 0 & 2 \\
\hline Microteléfono & 0 & 5 & 0 & 5 \\
\hline Tester Loop & 0 & 8 & 0 & 8 \\
\hline $\begin{array}{l}\text { Servidores } \\
\text { CANTV }\end{array}$ & 4 & 8 & 0 & 12 \\
\hline Total & 8 & 72 & 0 & 80 \\
\hline
\end{tabular}

Fuente: CANTV (datos desde febrero a julio 2019)

Tabla 2

Tareas de mantenimiento realizadas en los principales equipos y materiales

\begin{tabular}{|l|c|c|c|}
\hline $\begin{array}{l}\text { Equipo/tipo de } \\
\text { mantenimiento }\end{array}$ & $\begin{array}{c}\text { Preventivo } \\
\%\end{array}$ & $\begin{array}{c}\text { Correctivo } \\
\%\end{array}$ & $\begin{array}{c}\text { Predictivo } \\
\%\end{array}$ \\
\hline $\begin{array}{l}\text { Equipos de } \\
\text { computación }\end{array}$ & 3,85 & 96,15 & 0 \\
\hline Vehículos & 11,12 & 88,88 & 0 \\
\hline Ponchador & 0 & 100 & 0 \\
\hline Microteléfono & 0 & 100 & 0 \\
\hline Tester Loop & 0 & 100 & 0 \\
\hline Servidores CANTV & 33,34 & 66,66 & 0 \\
\hline
\end{tabular}

Fuente: CANTV (datos desde febrero a julio 2019)

Después de definir las funciones de los activos, se pueden identificar los puntos que no cumplen con las especificaciones o expectativas de operatividad establecidas por los usuarios. Luego de esto, es necesario precisar los modos de fallos, tanto para los activos físicos como para los lógicos. En tal sentido, cuando ocurre un fallo funcional, se debe identificar qué lo causa, es decir, el evento específico que provoca la existencia de este tipo de fallo; denominado como modo de fallo.

Normalmente para definir los modos de fallos de un activo es necesario considerar los fallos identificados por los usuarios o beneficiarios que pudieran causar probables fallos de carácter funcional. También es necesario precisar una relación de causalidad que posibilite la identificación de una gestión efectiva del manejo de fallos, a partir no solo de la identificación de los modos de fallos del pasado y del presente, sino, además, los modos de fallos que pudieran presentarse en el futuro.

El Análisis de Modos y Efectos de Falla (AMEF), según Maya (2018), constituye la herramienta principal de la metodología MCC. Por ello, este también será considerado en esta resemantización del modelo de mantenimiento en plataformas de telecomunicaciones y transmisión de datos; en general, se trata de una técnica sistemática que logra identificar las inconformidades antes de que estas ocurran y puedan generar graves consecuencias en los procesos y productos de un área determinada; su objetivo fundamental es encontrar los modos de fallos para prevenir sus consecuencias a partir de la ejecución oportuna de actividades de mantenimiento, que actuarán sobre cada modo de falla para prevenir sus posibles consecuencias. Un ejemplo de las hojas de información del Mantenimiento Centrado en Confiabilidad utilizadas se presenta en la Tabla 3.

Luego de realizar el análisis de modos de fallos, conviene evaluar los niveles de riesgos o prioridades que se deben tener en cuenta en el desarrollo de un plan de mantenimiento. Para lograr esto, se utiliza el análisis de criticidad definida por Knezevic (1996) como una técnica o procedimiento que permite categorizar instalaciones, sistemas, equipos y/o dispositivos en función de su impacto general; el objetivo de esta herramienta es optimizar los recursos económicos, humanos y técnicos. La definición de factor crítico dependerá del sistema que se esté estudiando y de los 
objetivos particulares de sus actores. En este caso particular se trata de activos físicos y lógicos, que se evaluarán a partir de cinco criterios fundamentales: frecuencia de fallo, impacto operacional, flexibilidad operacional, costos de mantenimiento e impacto en seguridad ambiente e higiene; estos elementos son clasificados en diferentes posibilidades de ocurrencia y son categorizados de acuerdo con el grado de importancia que tienen.

Tabla 3

Hoja de información MCC equipo 1

\begin{tabular}{|c|c|c|c|c|}
\hline $\begin{array}{l}\text { Equipo: } \\
\text { 1. Equipos de } \\
\text { computación } \\
\end{array}$ & \multirow{2}{*}{$\begin{array}{l}\text { Función: } \\
\text { Uso de Sistemas de información } \\
\text { Manejo de base de datos } \\
\text { Control de inventarios } \\
\text { Gestión de averías } \\
\end{array}$} & \multirow{2}{*}{$\begin{array}{l}\text { Elaborado por: } \\
\text { César Estaba }\end{array}$} & \multirow{2}{*}{$\begin{array}{l}\text { Fecha: } \\
\text { Octubre } \\
2019\end{array}$} & \multirow{2}{*}{$\begin{array}{l}\text { Página } \\
1 \text { de } 1\end{array}$} \\
\hline $\begin{array}{l}\text { Tipo: } \\
\text { Físico-lógico }\end{array}$ & & & & \\
\hline Falla funcional & Modo de fallo (Causa) & \multicolumn{3}{|c|}{ Efecto de fallo (ocurrencia posterior) } \\
\hline \multirow{4}{*}{$\begin{array}{l}\text { 1. No se tiene acceso } \\
\text { a sistemas de } \\
\text { información }\end{array}$} & A. Fallo de energía eléctrica & \multicolumn{3}{|c|}{ A. Imposible ubicación de fallo } \\
\hline & B. Datos de acceso incorrectos & \multicolumn{3}{|c|}{ B. Retrasos y retrabajo } \\
\hline & C. Sistemas en mantenimiento & \multicolumn{3}{|l|}{ C. Retrasos } \\
\hline & D. Errores en el sistema & \multicolumn{3}{|c|}{ D. Retrasos y retrabajo } \\
\hline \multirow{2}{*}{$\begin{array}{l}\text { 2. Base de datos } \\
\text { desactualizadas }\end{array}$} & A. Datos almacenados incorrectos & \multicolumn{3}{|c|}{ A. Retrasos y retrabajo } \\
\hline & $\begin{array}{l}\text { B. Mecanismos inadecuados de integridad y } \\
\text { seguridad }\end{array}$ & \multicolumn{3}{|c|}{ B. Retrasos y retrabajo } \\
\hline \multirow{2}{*}{ 3. Consultas espurias } & A. Datos almacenados incorrectos & \multicolumn{3}{|l|}{ A. Retrasos } \\
\hline & $\begin{array}{l}\text { B. Mecanismos inadecuados de integridad y } \\
\text { seguridad }\end{array}$ & \multicolumn{3}{|l|}{ B. Retrasos } \\
\hline \multirow{2}{*}{$\begin{array}{l}\text { 4. Asignación } \\
\text { inapropiadas de casos }\end{array}$} & A. Datos almacenados incorrectos & \multicolumn{3}{|c|}{ A. Retrasos y retrabajo } \\
\hline & $\begin{array}{l}\text { B. Mecanismos inadecuados de integridad y } \\
\text { seguridad }\end{array}$ & \multicolumn{3}{|c|}{ B. Retrasos y retrabajo } \\
\hline
\end{tabular}

Fuente: Elaboración propia

Los equipos estudiados fueron evaluados totalizando cada componente y obteniendo el valor general de criticidad, que será comparado con la matriz de criticidad establecida. A continuación, en la Tabla 4, se explica brevemente los elementos tradicionalmente utilizados en un análisis de criticidad.

Tabla 4

Definición de elementos críticos

\begin{tabular}{|c|c|c|}
\hline Elemento & Descripción & $\begin{array}{c}\text { Rango } \\
\text { Preestablecido }\end{array}$ \\
\hline Frecuencia de fallo & $\begin{array}{l}\text { Establece el número de veces que se repite } \\
\text { un evento considerado como falta dentro de } \\
\text { un período de tiempo establecido. }\end{array}$ & $1-4$ \\
\hline $\begin{array}{l}\text { Contexto } \\
\text { operacional }\end{array}$ & $\begin{array}{l}\text { Establece lo que se desea que el activo haga, } \\
\text { sin sobrepasar las características de diseño } \\
\text { de este, pero considerando el ámbito en el } \\
\text { que se desempeña el equipo. Son los efectos } \\
\text { causados en la producción cuando un equipo } \\
\text { o componente presenta un fallo dentro del } \\
\text { proceso productivo. }\end{array}$ & $1-10$ \\
\hline $\begin{array}{l}\text { Flexibilidad } \\
\text { operacional }\end{array}$ & $\begin{array}{l}\text { Representa la posibilidad de realizar un } \\
\text { cambio inmediato para continuar con la } \\
\text { producción sin incurrir en costos o pérdidas } \\
\text { considerables; se mide entre } 1 \text {, que } \\
\text { representa la existencia de alguna opción de } \\
\text { respaldo disponible, hasta el } 4 \text {, que expresa } \\
\text { la imposibilidad de realizar algún cambio } \\
\text { para restablecer la continuidad del servicio. }\end{array}$ & $1-4$ \\
\hline Costo & $\begin{array}{l}\text { Inversión en actividades de mantenimiento } \\
\text { operacional para mejorar la calidad del } \\
\text { servicio de telecomunicación y transmisión } \\
\text { de datos; donde } 1 \text { representa poca inversión } \\
\text { y } 4 \text {, suficientes recursos económicos. }\end{array}$ & $1-4$ \\
\hline $\begin{array}{l}\text { Impacto en } \\
\text { Seguridad Ambiente } \\
\text { e Higiene (SHA) }\end{array}$ & $\begin{array}{l}\text { Busca la medición de indicadores de } \\
\text { parámetros que reflejen la posibilidad de } \\
\text { daños hacia personas, instalaciones o medio } \\
\text { ambiente. Se mide en un rango de } 0 \text {, que } \\
\text { indica que no tiene ninguna incidencia, } \\
\text { hasta } 8 \text {, que indica que afecta } \\
\text { significativamente la seguridad del entorno. }\end{array}$ & $0-8$ \\
\hline
\end{tabular}

Fuente: Elaboración propia 
Para la evaluación del contexto operacional se utilizó la matriz de riesgo (¡Error! La autoreferencia al marcador no es válida.) establecida por Moubray (2004), pues esta permite determinar las acciones prioritarias dentro de una variedad de posibles operaciones; cabe señalar que esta se apoya en el denominado método GOD, el cual identifica las diferentes acciones que se deben realizar según los siguientes indicadores: Gravedad (Severidad), Ocurrencia y Detección. A continuación, se describe cada uno de estos. Gravedad: es un indicador utilizado para evaluar la magnitud o severidad que puede generar la ocurrencia de un modo de fallo. Ocurrencia: es la probabilidad de que un fallo específico ocurra en un tiempo determinado; esta medición se la realiza en una escala del 1 al 10. Detección: es un valor estimado que permite determinar, según una escala, la probabilidad de detectar un modo de fallo antes de que suceda.

Tabla 5

Evaluación de criticidad

\begin{tabular}{|c|l|l|l|}
\hline Intervalo & Severidad & Ocurrencia & Detección \\
\hline $9-10$ & $\begin{array}{l}\text { Puede afectar la } \\
\text { seguridad del } \\
\text { operador }\end{array}$ & $\begin{array}{l}\text { Muy alta } \\
\text { probabilidad de } \\
\text { ocurrencia }\end{array}$ & $\begin{array}{l}\text { Prácticamente } \\
\text { imposible de } \\
\text { detectar }\end{array}$ \\
\hline $6-8$ & $\begin{array}{l}\text { Afecta la } \\
\text { operatividad del } \\
\text { equipo }\end{array}$ & $\begin{array}{l}\text { Alta } \\
\text { probabilidad de } \\
\text { ocurrencia }\end{array}$ & $\begin{array}{l}\text { Baja } \\
\text { capacidad de } \\
\text { detección }\end{array}$ \\
\hline $3-5$ & $\begin{array}{l}\text { Moderado efecto } \\
\text { en la producción }\end{array}$ & $\begin{array}{l}\text { Moderada } \\
\text { probabilidad de } \\
\text { ocurrencia }\end{array}$ & $\begin{array}{l}\text { Alta } \\
\text { capacidad de } \\
\text { detección }\end{array}$ \\
\hline $1-2$ & Mínimo efecto & $\begin{array}{l}\text { Baja } \\
\text { probabilidad de } \\
\text { ocurrencia }\end{array}$ & $\begin{array}{l}\text { Muy alta } \\
\text { capacidad de } \\
\text { detección }\end{array}$ \\
\hline
\end{tabular}

Fuente: Elaboración propia

En general, este análisis de criticidad busca determinar los equipos o procesos que se consideran fundamentales en plataformas de telecomunicaciones y trasmisión de datos. Esta herramienta representa una metodología que puede ser cualitativa o cuantitativa. La medición se desarrolló a partir de la estimación de la ocurrencia de fallos, evaluación del impacto del fallo en el área operativa, económica, de seguridad humana y medio ambiente en el periodo de tiempo que va desde febrero a julio de 2019. Esta jerarquización de elementos críticos será la base que sustente el plan de mantenimiento para el tipo de plataformas tecnológicas estudiada en esta investigación. En la Tabla 6 se presenta la evaluación de criticidad, mientras que en la Tabla 7 se muestra la matriz de criticidad establecida de acuerdo a los siguientes parámetros: Frecuencia falla (FF); Contexto operacional (CO); Flexibilidad operativa (FO); Costo (CM); Impacto SHA (IS); Consecuencia $(\mathrm{COxFO}+\mathrm{CM}+\mathrm{IS})$.

Tabla 6

Evaluación de criticidad

\begin{tabular}{|l|c|c|c|c|c|c|}
\hline $\begin{array}{l}\text { Equipo/ } \\
\text { Parámetro }\end{array}$ & $($ FF) & $($ CO) & (FO) & (CM) & (IS) & $\begin{array}{c}\text { (COxFO)+CM+ } \\
\text { IS }\end{array}$ \\
\hline $\begin{array}{l}\text { Equipos de } \\
\text { computación }\end{array}$ & 221 & 8 & 3 & 2 & 0 & 26 \\
\hline Vehículos & 83 & 9 & 3 & 2 & 6 & 35 \\
\hline Ponchador & 15 & 3 & 1 & 1 & 1 & 5 \\
\hline Microteléfono & 9 & 4 & 2 & 1 & 0 & 9 \\
\hline Tester Loop & 8 & 4 & 2 & 1 & 1 & 10 \\
\hline Servidores CANTV & 65 & 8 & 4 & 2 & 0 & 34 \\
\hline
\end{tabular}


Tabla 7

Matriz de criticidad

\begin{tabular}{|l|c|c|c|l|}
\hline Equipo/Parámetro & $(\mathbf{F F})$ & $(\mathbf{C})$ & $\begin{array}{c}\text { Criticidad } \\
(\mathbf{F F x C})\end{array}$ & Estado \\
\hline $\begin{array}{l}\text { Equipos de } \\
\text { computación }\end{array}$ & 221 & 26 & 5746 & Crítico \\
\hline Vehículos & 83 & 35 & 2905 & Crítico \\
\hline Ponchador & 15 & 5 & 75 & Semicrítico \\
\hline Microteléfono & 9 & 9 & 81 & Semicrítico \\
\hline Tester Loop & 8 & 10 & 80 & Semicrítico \\
\hline Servidores CANTV & 65 & 34 & 2210 & Crítico \\
\hline
\end{tabular}

Para determinar el estado de criticidad se consideró lo establecido por Moubray (2004), que advierte que una relación de frecuencia de fallo (FF) multiplicado por la consecuencia (c) que genere un resultado mayor a 90 se considera "crítico", mientras que, si este factor se ubica entre 40 y 90 , se considera "semicrítico", y los que están por debajo de 40, "no críticos". En tal sentido, se observa que en la matriz de criticidad los elementos medulares son los equipos computacionales, vehículos y servidores.

\section{Fase IV: Diseño del plan}

Después de este recorrido para la resemantización del modelo de mantenimiento centrado en confiabilidad para plataformas de telecomunicación y trasmisión de datos, se llega a un punto determinante definido como el diseño del plan de mantenimiento, que recoge los resultados hasta ahora encontrados. El plan de mantenimiento de plataformas de telecomunicaciones mediante la metodología centrada en confiabilidad genera un análisis de los dispositivos críticos (físicos y lógicos) que se tienen disponibles y sus posibles requerimientos; también estudia el comportamiento de las variables denominadas fallos para ofrecer un plan de acción con responsables y acciones específicas en lapsos preestablecidos, de tal forma que se pueda evitar las interrupciones en los servicios o la pérdida de la información total o parcial.

Tanto en las redes de voz (telecomunicaciones) como en los sistemas de información, se busca alcanzar un mismo objetivo general: calidad de servicios. Para ello, es necesario mantener la operatividad de las redes o infraestructuras TIC. Para generar un plan de acción que sirva de soporte, la empresa CANTV tomó como referencia la filosofía de trabajo propuesta en COBIT, es decir, su esquema operativo para la gestión de plataformas tecnológicas. Este esquema operativo presenta diseño, políticas, mejores prácticas, metodologías y estrategias para gestionar eficientemente una infraestructura de tecnología de información.

De acuerdo con lo que establece la documentación COBIT para CANTV, entendida esta como una corporación tecnológica que monopoliza el sector de telecomunicaciones en Venezuela, la gestión general para el mantenimiento de plataformas de transmisión de datos se puede dividir en 4 grandes áreas, las cuales se definen a continuación:

Operación: representa el conjunto de procesos realizados para garantizar la funcionalidad de todos los elementos que conforman la red y se realiza en cada fase del diseño de cualquier tipo de red. Esta gestión proporciona una imagen clara de los elementos de red, desde su ubicación directa hasta la definición de responsabilidades y sus mecanismos de control.

Servicio: comprende el conjunto de comandos operativos realizados en los elementos que conforman la red, y los permisos que poseen los usuarios para realizar las tareas recurrentes. Facilita el almacenamiento de cambios realizados en la red y el resguardo de históricos operativos. Incluye el registro de usabilidad de la red y los servicios que provee esta. De esta forma se obtienen los costos asociados a la tecnología existente. Por medio de esta gestión se realizan todos aquellos cálculos estadísticos de interfaces y protocolos. 
Calidad: representa el grupo de funciones que habilita la identificación, aislamiento y/o depuración de operaciones irregulares de la red. El principal objetivo de esta gestión es detectar, registrar y corregir los eventos típicos o atípicos que ocurren en la red.

Control: mecanismo de garantía que permite confiar en que la información transmitida entre los elementos de la red sea correcta y completa, desde el emisor hasta el receptor; también asegura la seguridad en el manejo de los datos mediante mecanismos de confidencialidad, integridad y disponibilidad de la información.

En definitiva, los servicios de telecomunicaciones y transmisión de datos se proporcionan según las características y condiciones inherentes a los propios equipos tecnológicos de los que dispone CANTV y a la convergencia entre todas sus redes. Desde el punto de vista de las redes orientadas a servicios de voz y datos, la gestión de estas plataformas se refiere al conjunto de actividades que se realizan para coordinar y controlar los recursos que soportan las comunicaciones. Este control asegura la operatividad de los servicios que ofrece esta empresa de telecomunicaciones, para lo que se requiere gestionar las redes (por ser el entorno que hace posible la comunicación entre los usuarios y la plataforma) y toda aquella plataforma tecnológica o TIC donde residen los servicios.

En general, la gestión del modelo de mantenimiento de plataformas de telecomunicación y trasmisión de datos incluye integración y coordinación de hardware, software y de todos los elementos asociados con la evaluación, prueba y configuración de los recursos de la red para conseguir los requerimientos de tiempo real, desempeño operacional y calidad de servicio a un costo de equilibrio, es decir, en donde el costo de los servicios sea considerado por la calidad del servicio y su costo de operatividad.

CANTV debe definir sus operaciones internas y externas para mejorar los flujos de información. Esto se traducirá en eficiencia a la hora de brindar servicios de telecomunicación a los usuarios finales.

El mantenimiento de plataformas de telecomunicaciones debe ser concebido mediante elementos de planeación, análisis, diseño, desarrollo, implantación y evaluación de resultados, que permitan cuantificar la necesidad económica para la gestión de mantenimientos en este tipo de sector productivo. Se recomienda generar un esquema operativo a partir de la identificación de las mejores prácticas, de tal forma que se permitan el establecimiento de un estándar de calidad, útil y actualizable, para la organización acorde con las aspiraciones de los usuarios de CANTV.

\section{Fase V: Reconceptualización}

El modelo de mantenimiento centrado en confiabilidad establece las actividades de mantenimiento con sus respectivas frecuencias para los activos más importantes (considerados como críticos) de acuerdo con su análisis funcional dentro del marco operacional esperado. Este esquema de trabajo representa un proceso de gestión de mantenimiento donde el equipo de trabajo maximiza la confiabilidad operacional y la continuidad de un servicio dentro de un sistema que funciona bajo condiciones de trabajo bien definidas. Su éxito está directamente relacionado con el desempeño que demuestra este equipo en el momento de proporcionar un sistema de gestión de mantenimiento integral que se adapte a los verdaderos requerimientos de los usuarios o clientes de CANTV. Para lograr este fin, es necesario contar con los elementos asociados a la seguridad personal, el ambiente, las operaciones y el costo beneficio, tal como lo define la MCC y la filosofía COBIT.

Del nuevo esquema metodológico propuesto en esta investigación, denominado Mantenimiento Confiable para Plataformas de Telecomunicaciones (MCPT), se han desarrollado de modo implícito y explícito hasta ahora las siguientes etapas y subetapas:

\section{Etapa I}

Identificación del negocio: reconocimiento de los objetivos y las estrategias de la organización, la estructura operacional y las políticas definidas para el mantenimiento. 


\section{Etapa II}

TI.

Estudio de la plataforma TI; revisión de equipos y componentes y estudios de los procesos de

\section{Etapa III}

Análisis de fallos: determinación de fallos funcionales; identificación de modos de fallos; estudio de consecuencia de fallos.

\section{Etapa IV}

Diseño de medidas pertinentes: definición de medidas proactivas; definición de medidas preventivas; definición de medidas predictivas; definición de medidas correctivas.

Para culminar con la aplicación de dicha metodología, solo resta el desarrollo de la Etapa V. Esta etapa consiste en la elaboración de un plan de mantenimiento centrado en confiabilidad, que, a su vez, incluya las siguientes tareas: integración del plan, documentación del plan, revisión y pruebas y presentación de resultados.

\section{Discusión}

Es precisamente en este punto de la investigación en donde se reflexiona sobre los resultados obtenidos en el desarrollo de las fases de la metodología. En este sentido, el mantenimiento de plataformas de telecomunicación es un proceso continuo que estudia la conexión de equipos que interactúan entre sí, lo que permite la transmisión datos de forma rápida y segura. Sin embargo, para poder optimizar este proceso es fundamental que se realice un plan de mantenimiento de estas telecomunicaciones para activar mecanismos de solución ante cualquier interrupción que perturbe la continuidad del servicio. Este trabajo de investigación tiene el propósito de presentar un producto innovador de gran proyección que pueda ser replicado en otros contextos similares o en corporaciones nacionales o internacionales del mismo sector.

La etapa de implementación tiene como objetivo principal la ejecución de las actividades diseñadas en las fases previas, así como la definición de las directrices generales para su puesta en marcha. A pesar de que la aplicación de la propuesta no forma parte de esta investigación, a continuación, se sugieren 4 condiciones que facilitarían su ejecución y presentación de resultados.

1. Adaptación de la estructura organizacional: CANTV debe realizar una reingeniería de sus esquemas operativos para adaptarlos a los nuevos escenarios tecnológicos, y, de esta forma, hacer frente a las exigencias actuales y potenciales de sus usuarios.

2. Adecuación del clima organizacional: dentro del proceso de aplicación del plan, debido al sector tecnológico y a la situación social, política y económica que atraviesa el país, la adecuación del clima organizacional representa la tarea de mayor complejidad. Y esto en gran parte por la resistencia al cambio que se podría generar entre los actores y las gerencias que conforman la estructura organizacional actual. Para fomentar mejoras en el clima organizacional encaminadas a construir una nueva cultura de mantenimiento se sugiere comunicar los beneficios esperados, transmitir los objetivos y las metas establecidas, e integrar a todos los actores en cada una de las fases de implementación del modelo de mantenimiento.

3. Desarrollo de actividades: permite exponer a todo el personal las principales tareas que se deben ejecutar para el cumplimiento de los objetivos. Es importante reflejar el origen, propósito y descripción de cada actividad. Además, es importante señalar que el análisis de capacidades y potencialidades de los actores debe ser tomado en consideración. Se deben explicar los recursos necesarios para el desarrollo armónico de estas actividades y el plan de formación que pudieran requerir de acuerdo con la realidad organizacional y operativa. 
4. Revisión continua: una vez realizada la implantación de actividades se sugiere hacer un seguimiento a través de mediciones de gestión; lo que se busca con esto es visualizar los resultados obtenidos (y por obtener) con la incorporación de una nueva filosofía de mantenimiento, que resalte las desviaciones que pudieran surgir para tomar las medidas pertinentes de forma oportuna y, de este modo, optimizar los recursos y garantizar la calidad del servicio de telecomunicaciones y transmisión de datos.

La evaluación metodológica consiste en medir los resultados obtenidos al aplicar la guía de pasos establecida como marco de referencia conceptual y operacional, es decir, verificar utilizando una lista de cotejo o check list como herramienta de identificación inicial. Paso previo para avanzar en un análisis detallado de eficiencia de los equipos a partir de la identificación de los indicadores clásicos normalmente esperados en todo programa de mantenimiento. En este sentido, a continuación, se proponen 3 categorías evaluativas que se podrían tomar en cuenta.

Mediciones cuantitativas: consiste en realizar mediciones numéricas en relación con la gestión de mantenimiento. Entre ellas se sugiere medir los indicadores propuestos, antes, durante y después de la ejecución del programa de mantenimiento, lo cual permitirá realizar comparaciones entre los resultados para tomar las acciones correspondientes y proponer los cambios que se requieran.

\section{Figura 3}

Esquema general de confiabilidad operacional para el mantenimiento de plataformas de telecomunicación y trasmisión de datos

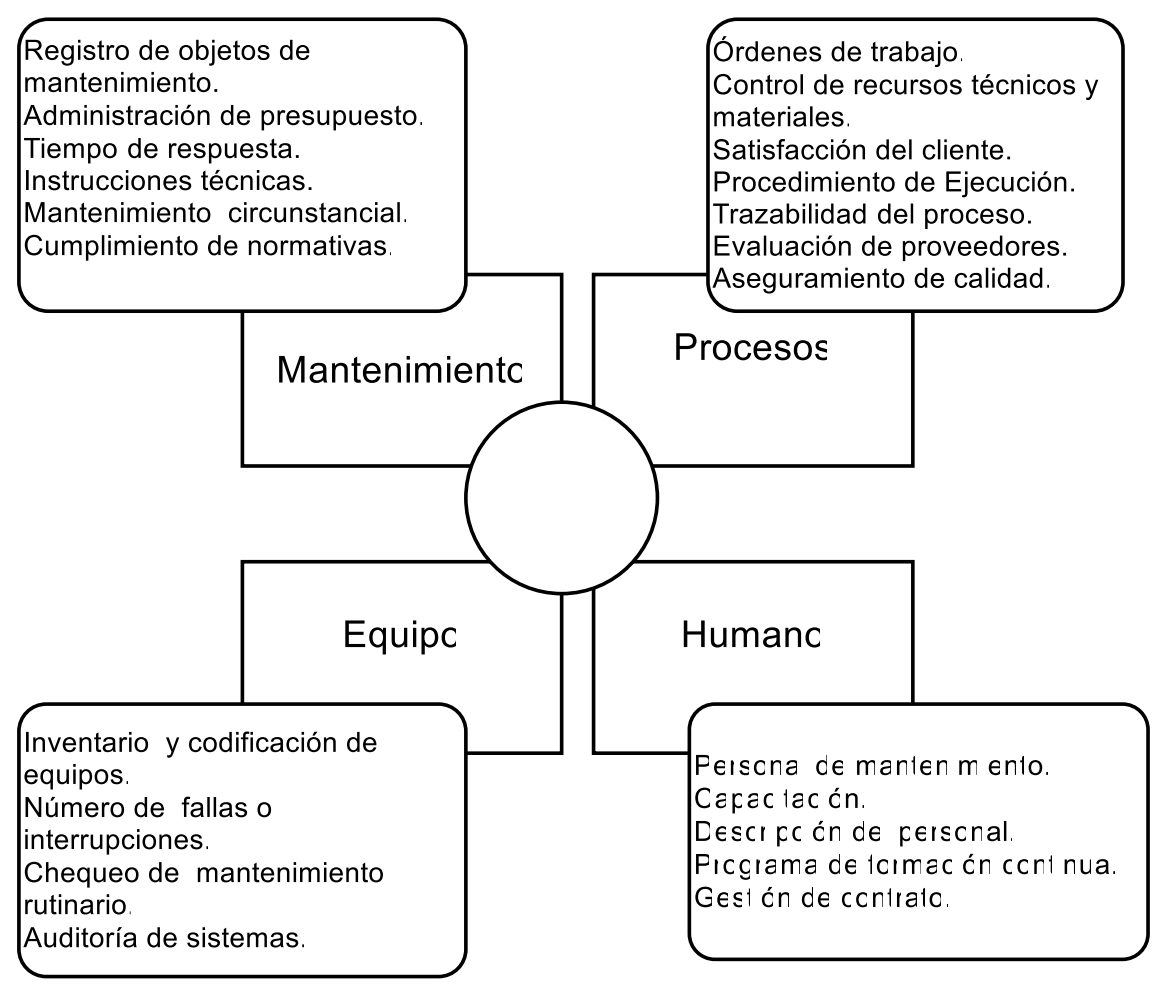

Fuente: Elaboración propia

Mediciones cualitativas: son aquellas evaluaciones relacionadas a los atributos o cualidades subjetivas que han surgido de la interpretación personal de los involucrados. No son tan precisas como las mediciones cuantitativas, pero ofrecen un nivel de participación mayor, porque se trata de análisis simples que no requieren gran inversión de tiempo.

Evaluación externa: consiste en mediciones de especialistas en el área de mantenimiento y tecnología (internos y externos), que aportan, desde su perspectiva, una noción técnica de los resultados obtenidos en la aplicación de la metodología. 
En definitiva, la planificación del mantenimiento centrado en confiabilidad para plataformas de telecomunicación y trasmisión de datos en la empresa CANTV tiene como objetivo definir cómo, cuándo y dónde se deben realizar las diferentes instrucciones técnicas para cada objeto que requiere mantenimiento. La planificación puede establecerse para periodos anuales, semestrales, mensuales, semanales o diarios, dependiendo de la dinámica del proceso y del conjunto de actividades que requieran ser programadas para lograr las expectativas planteadas. Finalmente, en la Figura 3, se presenta el esquema general de confiabilidad operacional para el mantenimiento de plataformas de telecomunicación y trasmisión de datos.

\section{Conclusiones}

Luego de estudiar el contexto internacional y nacional del negocio de las telecomunicaciones y la transmisión de datos, se identificaron los elementos determinantes del modelo centrado en confiabilidad para su adecuación en este tipo de plataformas, lo que, a su vez, permitió identificar los principales factores críticos: presencia de mecanismos regulatorios, baja rentabilidad del negocio en el país y falta de planes formales de mantenimiento. A partir de este diagnóstico, se propuso como esquema operativo para el diseño de programas de mantenimiento en la empresa CANTV la Metodología de Mantenimiento Confiable para Plataformas de Telecomunicaciones (MCPT).

El estudio de la infraestructura de telecomunicaciones y transmisión de datos generó un diagnóstico integral de las condiciones actuales en la corporación, que se permitió contar con un estudio del entorno específico de CANTV, los aspectos legales involucrados, los recursos disponibles y el establecimiento de requerimientos técnicos para mejorar el servicio ofrecido.

Mediante el análisis del esquema de fallos y los niveles de criticidad, considerados como medidas de prevención y control de operaciones, se lograron determinar que los equipos y las herramientas que presentan mayor incidencia de averías -y por lo tanto, requieren mayor atención en los programas de mantenimiento- son computadores, vehículos, ponchador, microteléfono, tester loop y servidores. Esta situación pudo ser demostrada mediante la aplicación de la matriz de criticidad, inherente a la metodología desarrollada.

Luego de haber definido la gestión para el mantenimiento de plataformas tecnológicas, el establecimiento de indicadores de gestión y la identificación de mejores prácticas de mantenimiento, se diseñó un plan de acción acorde con esquema de fallos y los niveles de criticidad para la activación oportuna de medidas preventivas. Dentro de este proceso cabe resaltar la importancia que tuvo el desarrollo de auditorías programadas para los equipos y sistemas.

La redefinición de la concepción técnica y operativa del modelo de mantenimiento centrado en confiabilidad permitió generar un esquema conceptual y práctico inédito para el control de fallos en plataformas de telecomunicaciones y transmisión de datos, lo que permitió generar fundamentos innovadores para este tipo de actividades. Este logro permite optimizar de forma integral los recursos, al mismo tiempo que satisfacer al cliente mediante la propuesta de un programa general de mantenimiento confiable para plataformas de telecomunicaciones. En este caso, aplicado en la empresa CANTV, pero que pudiera llevarse con igual éxito a otras organizaciones similares.

\section{Referencias}

Arias, F. (2006). El proyecto de investigación. Caracas, Venezuela: Editorial Episteme,

Balladares, J. (2017). Parámetros de calidad del servicio de acceso a Internet en redes convergentes y construcción de una sonda para la medición de parámetros de velocidad de descarga, velocidad de subida, tiempo de ping y latencia para usuarios finales del servicio de acceso a Internet para la coordinación zonal 4 de la agencia de regulación y control de las telecomunicaciones [Tesis de Maestría, Pontificia Universidad Católica del Ecuador].

http://repositorio.puce.edu.ec/bitstream/handle/22000/13490/Tesis\%20final\%20Jorge\%20Balladares.p 
df? sequence $=1 \&$ isAllowed $=\mathrm{y}$

Bravo, F. (2016). Elaboración de un plan de mantenimiento centrado en confiabilidad [Tesis de Grado, Universidad Central de Venezuela, Cagua]. http://saber.ucv.ve/bitstream/123456789/16893/1/Trabajo\%20Final\%20de\%20Grado\%20Fabi\%C3\% A1n\%20Bravo.pdf

García, C. (2015). Modelo de gestión de mantenimiento para incrementar la calidad en el servicio en el Departamento de alta tensión de STC Metro de la ciudad de México [Tesis de Maestría, Instituto Politécnico Nacional]. https://docplayer.es/51084249-Instituto-politecnico-nacional-unidadprofesional-interdisciplinaria-de-ingenieria-y-ciencias-sociales-y-administrativas.html

Hurtado, J. (2007). El proyecto de investigación. Metodología de la investigación holística. Caracas, Venezuela: Editorial Sypal.

Knezevic, J. (1996). Mantenibilidad. España: Editorial Isdefe.

Ley Orgánica de Telecomunicaciones (2011). Publicada en la Gaceta Oficial de la República Bolivariana de Venezuela. 7 de febrero de 2011, D.O. No. 39.610.

Maya, J. (2018). Aplicación de RCM como estrategia de implementación del mantenimiento predictivo para la metodología TPM. [Tesis de Maestría, Universidad Nacional de Colombia. Facultad de Minas, Departamento de Ingeniería Mecánica] https://repositorio.unal.edu.co/bitstream/handle/unal/64727/98702383.2018.pdf?sequence=1\&isAllow $\mathrm{ed}=\mathrm{y}$

Mora, A. (2009). Mantenimiento. Planeación, ejecución y control. Alfaomega Grupo Editor, México.

Moubray, J. (2004). Mantenimiento Centrado en Confiabilidad. EUA: E. Brothers.

Orbe, M. (2017). Propuesta metodológica de analítica de datos para estudio y análisis de tráfico en redes de telecomunicaciones. [Tesis de Maestría, Escuela Politécnica Nacional]. https://bibdigital.epn.edu.ec/bitstream/15000/19046/1/CD-8442.pdf

Rivas, E. (2017). Modelo teórico de un sistema de gestión de mantenimiento basado en los principios de la gerencia de proyectos. [Tesis de Maestría, Escuela Politécnica Nacional]. http://biblioteca2.ucab.edu.ve/anexos/biblioteca/marc/texto/AAQ9426.pdf

Romero, E. (2019). El aislamiento como estrategia. Rezago, empobrecimiento de la calidad y censura a medios digitales. Caracas. Venezuela: Sector de Telecomunicaciones.

Villacrés, S. (2016). Desarrollo de un plan de mantenimiento aplicando la metodología de Mantenimiento Basado en la Confiabilidad (RCM) para el vehículo hidrocleaner vactor m654 de la empresa Etapa EP. [Tesis de Maestría, Escuela Superior Politécnica de Chimborazo]. http://dspace.espoch.edu.ec/bitstream/123456789/4749/1/20T00717.pdf

Wither, N. (2014). Diseño de un plan de auditoría interna de sistemas, para un modelo de aerolínea doméstica ecuatoriana, basado en análisis de riesgos, y tomando como marco de referencia COBIT 5. [Tesis de Grado. Universidad Católica de Santiago de Guayaquil]. http://repositorio.ucsg.edu.ec/bitstream/3317/2822/1/T-UCSG-PRE-ECO-MD-CICA-5.pdf

Zecchetto, V. (2011). El persistente impulso a resemantizar. Revista de Ciencias Sociales y Humanas, 14, pp. 127-142. 